\title{
Correlation between plate age and layer separation of double seismic zones*
}

\author{
Keliang Zhang ${ }^{1, \star}$ and Dongping $\mathrm{Wei}^{2,3}$ \\ ${ }^{1}$ State Key Laboratory of Earthquake Dynamics, Institute of Geology, China Earthquake \\ Administration, Beijing 100029, China \\ ${ }^{2}$ Key Laboratory of Computational Geodynamics, Chinese Academy of Sciences, Beijing 100049, China \\ ${ }^{3}$ College of Earth Science, Graduate University of Chinese Academy of Sciences, Beijing 100049, China
}

\begin{abstract}
Global seismicity catalogs are sufficient for characterizing double seismic zones (DSZs) in subducting slab and facilitate to estimate layer separation without inconsistent uncertainties as local catalogs. Previous studies have shown the correlation between DSZs layer separation and plate age while correlation for those younger than $\sim 60 \mathrm{Ma}$ is suspicious. The lacking of DSZs with layer separation less than $10 \mathrm{~km}$ further makes it difficult to precisely estimate such correlation. Thus, we incorporate eight DSZs data determined through local seismicity into globally-determined dataset and reexamine such correlation. The best fitting results show that both a linear model and a square root of plate age can mathematically fit the layer separation well. However, it is difficult to distinguish these two models when plate age is greater than $\sim 20 \mathrm{Ma}$ since their difference is less than $2 \mathrm{~km}$. However, if extrapolation is possible, both models should provide physical information that DSZs will not form if there is no subducting lithosphere. As a result, the DSZs cannot be produced until the oceanic lithospheric age becomes greater than $0.9 \mathrm{Ma}$ in the square root model while the linear model gives a misleading result. As such the square root model demonstrates the relationship physically better than the linear one, it still needs further test in the future with more available data, nevertheless, our study might also provide evidence for the suggestion that the plate age is a primary control factor of the DSZs geometry as well as the subducting process which disregards any local tectonic stresses.
\end{abstract}

Key words: double seismic zone; layer separation; plate age; correlation; best fitting CLC number: P315.01 Document code: A

\section{Introduction}

As the oceanic lithosphere departs away from the mid-ocean ridge, it cools step by step and becomes progressively denser, subsides, and thickens with the increasing age due to thermal contraction. Relationships among age and oceanic depth, heat flow, and lithospheric thickness demonstrate the property variations of the oceanic lithosphere depending upon its age (Wiens and Stein, 1983; Stein and Stein, 1992; Carlson and Johnson, 1994; Turcotte and Schubert, 2002; Harmon et al., 2009). The plate age also plays a primary role on various

\footnotetext{
* Received 27 September 2011; accepted in revised form 28 December 2011; published 10 February 2012.

* Corresponding author. e-mail: keliang_zhang@hotmail.com

(C) The Seismological Society of China, Institute of Geophysics,

China Earthquake Administration, and Springer-Verlag Berlin Heidelberg 2012
}

subduction zone parameters including slab dip angle, subducting rate and thickness of subducting slab, etc. (Jarrard, 1986; Lallemand et al., 2005). Earthquakes occurring at depths $>70 \mathrm{~km}$ provide direct evidence for the details of subducting slabs. Specifically speaking, the older plates usually present thicker seismic zone. However, recent studies have suggested that the role of plate age seems to be somewhat doubtful and need to be reevaluated (Cruciani et al., 2005; Lallemand et al., 2005).

On the other hand, the stress pattern of subduction zones can be generally delineated by either down-dip compression (DDC) due to the resistance by the viscous mantle or down-dip tension (DDT) being extended by slab pull, respectively (Isacks and Molnar, 1969; Chen et al., 2004). This pattern is in agreement with the observations in some cases, whereas some other slabs present 
more complicated stresses or even rather down-dip. For example, in many subduction zones, most intermediatedepth earthquakes occur in two distinct layers, which are separated vertically by an aseismic belt and form double seismic zones (DSZs) (e.g., Hasegawa et al., 1994; Kao and Rau, 1999; Brudzinski et al., 2007). Though DSZs demonstrate the stress regime only over a small range $(\sim 5 \%)$ of intermediate-depth seismicity (Chen et al., 2004), they might provide evidence for better understanding the mechanism of intermediate-depth earthquakes, and further become an important constraint on the subduction dynamic models (Kawakatsu, 1986; Wang and Rogers, 1994; Zhang and Wei, 2008, 2011).

The aseismic belt between DSZs indicates that Wadati-Benioff zone (WBZ) earthquakes are tending to occur along both the upper and lower parts of the brittle portion of subducting slabs (Suzuki and Kasahara, 1996; Wang, 2002). The thickness of the aseismic belt (refers to layer separation hereinafter) becomes an important feature depicting both the DSZs and slab geometry (Hacker et al., 2003; Brudzinski et al., 2007). However, there is no uniform depth where DSZs are ready to form; in most studies, DSZs are reported to form at depths from 50 to $100 \mathrm{~km}$ and layer separation in this study is referred to the perpendicular distance between the beginnings of two seismic zones. Most layer separations seem to vary with the plate ages. For example, for the first convincing DSZs beneath Tohoku, the layer separation is of $\sim 30 \mathrm{~km}$ with a $\sim 130 \mathrm{Ma}$ aged Pacific ocean plate (Hasegawa et al., 1994; Yamasaki and Seno, 2003; Hacker et al., 2003), whereas for DSZs in the southwest Japan, the layer separation is of $\sim 10 \mathrm{~km}$ with a $\sim 20$ Ma aged Philippine Sea plate (Ohmi and Hori, 2000). In contrast, though the lithospheric ages increase along the arc from Kamchatka to the Kuril, three DSZs along this arc are comparable with that of Tohoku in both layer separation and the maximum depth extent (Gorbatov et al., 1994; Kao and Chen, 1995; Kao and Liu, 1995). This contradiction of relationship between layer separation and age might be significantly influenced by the uncertainties of either plate age or locating precision of earthquakes due to different local networks (Abers, 1996).

Recently, Brudzinski et al. (2007) have determined layer separations of 32 segments of DSZs worldwide from global catalogs and have shown their correlation with the plate age. More recently, correlation analysis on DSZs and subduction parameters has shown that layer separations are linearly correlated with plate age while those of younger $(<60 \mathrm{Ma})$ ones are also affect- ed by local stress state (Zhang and Wei, 2011). Thus, the linear correlation between layer separation and plate age is needed to be reexamined.

\section{Data}

Global seismicity catalogs may be sufficient for characterizing DSZs and will facilitate the estimate of layer separation without inconsistent uncertainties as local catalogs (Brudzinski et al., 2007). However, it is difficult to detect DSZs with layer separation less than $10 \mathrm{~km}$ using global catalogs because the location precision is about $10 \mathrm{~km}$. The lacking of thinner layer separated DSZs might make it difficult to precisely estimate the correlation between DSZs layer separation and plate age. In fact, many researchers have reported DSZs with layer separation less than $10 \mathrm{~km}$ in Juan de Fuca plate and Nazca plate since 1990s (Wang and Rogers, 1994; Cassidy and Waldhauser, 2003; Comte and Suarez, 1994; Comte et al., 1999; Rietbrock and Waldhauser, 2004). Thus, we collected 39 DSZs by incorporating data of these four thinner DSZs and four DSZs along Kamchatka-Kuril determined through local seismicity into globally-determined dataset after Brudzinski et al. (2007). The present-day plate ages at 34 trenches are directly taken from or interpolated from the most upto-date dataset age.3.6.xyz (http://www.earthbyte.org) based on the work by Müller et al. (2008), and the remainder five plate ages, including Middle America and Tonga, are modified from the data after Sdrolias and Müller (2006), Brudzinski et al. (2007) and/or Lallemand et al. (2005) at several subduction zones. All the datasets used here are the same as those by Zhang and Wei (2011) and the positions of these subduction zone segments are shown in Figure 1.

\section{Best fitting models for layer sep- aration $(L)$ of DSZs and plate age $(A)$}

As there is a strong correlation between layer separation and plate age (correlation coefficient is 0.83 ), we would like to find suitable coefficients $a$ and $b$ so that we can represent $L$ using a best fit line $L=a A+b$ within the range of the data with the least squares method, and we obtain the expression,

$$
L=0.15 A+6.55 \text {. }
$$

It has been proven that the predictions from the plate model, especially the global depth and heat flow 


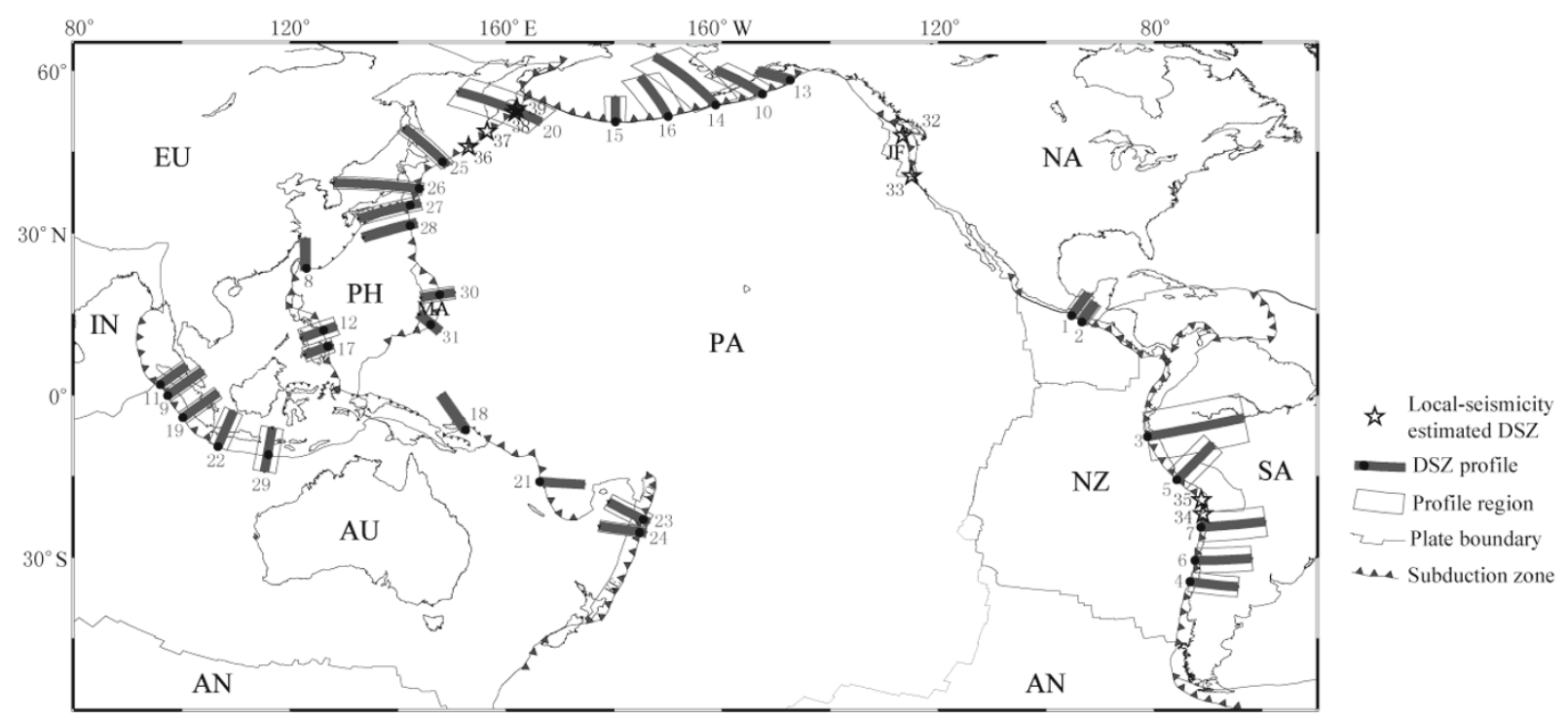

Figure 1 Regional profiles of 39 double seismic zones. Plate abbreviations are AN, Antarctic; AU, Australia; EU, Eurasia; JF, Juan de Fuca; MA, Mariana; IN, India; NA, North America; NZ, Nazca; PA, Pacific; PH, Philippine Sea plate; SA, South America.

(GDH1) model (e.g., Stein and Stein, 1992), match the variations of both bathymetry and heat flow much better than those from the cooling half-space model. Nevertheless, it flattens the observations from both bathymetry and heat flow when plate age is greater than $\sim 80$ Ma. According to the half-space model, the lithospheric thickness depends on the square root of plate age (Carlson and Johnson, 1994), and thus might do the layer separation of double seismic zones. The correlation coefficient between layer separation and square root of plate age is also 0.83 . We then obtain their best fitting expression as follows:

$$
L=2.44 A^{1 / 2}-2.36 .
$$

The predictions and residuals for both models ( $\mathrm{Ta}-$ ble 1) are shown in Figures 2 and 3, respectively. An Ftest for the residuals of both models shows that the improvement from the square root model is not significant even at the $75 \%$ confidence level because the standard deviations of the residuals are statistically identical to each other (Figures 3a, b). The difference between two models becomes insignificant (with difference less than 2 $\mathrm{km}$ ) when the plate age is greater than $\sim 20 \mathrm{Ma}$ (Figure $3 \mathrm{c})$.

\section{Discussion and conclusions}

The best-fitting process shows that the layer separation is correlated with the plate age in both the linear and square root models. It is essential to declare that a simply correlation is statistically possible for these two variables to be related, but not have one variable cause another. However, for the most important constraint, DSZ would never come into being at least before the oceanic lithosphere initially formed. From this viewpoint, and if both expressions (1) and (2) can be extrapolated to the places where DSZs originally for$\mathrm{m}$, the minimum plate ages producing DSZs should be estimated; and thus the square root model might be more reasonable since the DSZs cannot be produced until the oceanic lithospheric age becomes greater than $0.9 \mathrm{Ma}$ while the linear model might give a misleading result. Once the oceanic lithosphere becomes older than a certain age, for example $20 \mathrm{Ma}$, the layer separation of DSZs can be estimated using both models. If more DSZs are detected, the correlation between layer separation and plate age will be more reasonably and/or better estimated and/or explained, and test whether the extrapolation to younger plates is correct.

We do not exclude any data for both best-fitting cases because any outlier exceeding the error level of 95\% confidence may reflect the local or regional tectonic processes, nevertheless we cannot estimate their exact influence by far. The removal of outliers might give a more perfect mathematical expression; however, it in turn may change the physical interpretation if the outlier is real data. For example, along the trench from the Kamchatka to the Kurile and the Japan arc, the plate ages generally increase from north to south (Müller et al., 2008), and the DSZ layer separations are expected 
to increase with age but that of No. 25 DSZ (SKUR) is much less than the predicted value. This layer separation would be further modified with more detailed seismicity catalog; and a complex local tectonic process can not be excluded without further validation.

Our results indicate that layer separation of young DSZs varies with the square root of age while those of old ones change linearly with age. This is in contrast with plate model, which indicates thickness of ocean- ic lithosphere older than 70 Ma evolves asymptotically toward constant values. Though plate age itself is far from sufficient to interpret the origin of DSZs (Kao and Rau, 1999; Yamasaki and Seno, 2003; Hacker et al., 2003), our results show that plate age represents at least the primary factor controlling the seismicity of subduction zones. That is, the older subducting slabs usually present thicker aseismic zone because these slabs have thicker regions of low temperatures. Recently, numerous

Table 1 Fitting models of DSZs layer separation $(L)$ and plate age $(A)$

\begin{tabular}{|c|c|c|c|c|c|c|c|c|c|}
\hline \multirow{2}{*}{ DSZ } & \multirow{2}{*}{ Name } & \multicolumn{2}{|c|}{ Location } & \multicolumn{2}{|c|}{ Plate age } & \multicolumn{2}{|c|}{ Layer separation } & \multicolumn{2}{|c|}{ Fitting models } \\
\hline & & Long. $/{ }^{\circ} \mathrm{E}$ & Lat. & $A / \mathrm{Ma}$ & Ref & $L / \mathrm{km}$ & Ref & Linear $/ \mathrm{km}$ & $\mathrm{SR}^{*} / \mathrm{km}$ \\
\hline 1 & ME1 & 265 & $15^{\circ} \mathrm{N}$ & 24 & $\mathrm{M}, \mathrm{S}$ & 8 & $\mathrm{~B}$ & 10.1 & 9.5 \\
\hline 2 & ME2 & 267 & $14^{\circ} \mathrm{N}$ & 25 & $\mathrm{M}, \mathrm{S}$ & 8 & B & 10.2 & 9.8 \\
\hline 3 & PE1 & 279 & $8^{\circ} \mathrm{S}$ & 29 & M & 16 & B & 10.8 & 10.7 \\
\hline 4 & $\mathrm{SC} 1$ & 287 & $35^{\circ} \mathrm{S}$ & 36 & M & 11 & B & 11.9 & 12.2 \\
\hline 5 & NZ1 & 284 & $16^{\circ} \mathrm{S}$ & 46 & M & 8 & B & 13.4 & 14.1 \\
\hline 6 & NZ2 & 288 & $31^{\circ} \mathrm{S}$ & 40 & M & 13 & B & 12.5 & 13 \\
\hline 7 & $\mathrm{NC} 1$ & 289 & $24^{\circ} \mathrm{S}$ & 48 & M & 11 & B & 13.7 & 14.5 \\
\hline 8 & TW & 123 & $23^{\circ} \mathrm{N}$ & 56 & M & 17 & B & 14.9 & 15.8 \\
\hline 9 & WA1 & 97.3 & $0^{\circ}$ & 46 & $\mathrm{~B}, \mathrm{~L}$ & 16 & B & 13.4 & 14.1 \\
\hline 10 & EA1 & 208 & $56^{\circ} \mathrm{N}$ & 48 & $\mathrm{M}$ & 14 & B & 13.7 & 14.5 \\
\hline 11 & SUM1 & 95.9 & $1.9^{\circ} \mathrm{N}$ & 51 & $\mathrm{~B}, \mathrm{~L}$ & 14 & B & 14.2 & 15 \\
\hline 12 & PH1 & 126 & $12^{\circ} \mathrm{N}$ & 76 & $\mathrm{M}$ & 17 & B & 17.9 & 18.8 \\
\hline 13 & EA2 & 213 & $58^{\circ} \mathrm{N}$ & 40 & $\mathrm{~L}$ & 12 & B & 12.5 & 13 \\
\hline 14 & WA2 & 199 & $54^{\circ} \mathrm{N}$ & 52 & $\mathrm{~L}$ & 22 & B & 14.3 & 15.1 \\
\hline 15 & CA1 & 180 & $51^{\circ} \mathrm{N}$ & 52 & M & 14 & B & 14.3 & 15.1 \\
\hline 16 & $\mathrm{CA} 2$ & 190 & $52^{\circ} \mathrm{N}$ & 60 & M & 14 & B & 15.5 & 16.5 \\
\hline 17 & PH2 & 127 & $9^{\circ} \mathrm{N}$ & 99 & M & 16 & B & 21.4 & 21.8 \\
\hline 18 & NB1 & 153 & $7^{\circ} \mathrm{S}$ & 83 & M & 15 & B & 19 & 19.8 \\
\hline 19 & SUM2 & 100 & $4^{\circ} \mathrm{S}$ & 73 & M & 16 & B & 17.5 & 18.4 \\
\hline 20 & Kam1 & 162 & $52^{\circ} \mathrm{N}$ & 104 & M & 19 & B & 22.2 & 22.4 \\
\hline 21 & HEB & 166 & $16^{\circ} \mathrm{S}$ & 39 & M & 19 & B & 12.3 & 12.8 \\
\hline 22 & JAV1 & 107 & $10^{\circ} \mathrm{S}$ & 105 & $\mathrm{M}$ & 19 & B & 22.3 & 22.6 \\
\hline 23 & TON & 185 & $23^{\circ} \mathrm{S}$ & 89 & $\mathrm{M}, \mathrm{S}$ & 22 & B & 19.9 & 20.6 \\
\hline 24 & KER & 185 & $25^{\circ} \mathrm{S}$ & 86 & $\mathrm{M}, \mathrm{S}$ & 27 & B & 19.4 & 20.2 \\
\hline 25 & SKUR & 148 & $43^{\circ} \mathrm{N}$ & 120 & $\mathrm{M}$ & 15 & B & 24.6 & 24.3 \\
\hline 26 & JAP & 144 & $38^{\circ} \mathrm{N}$ & 132 & M & 30 & B & 26.4 & 25.6 \\
\hline 27 & NIZ & 142 & $35^{\circ} \mathrm{N}$ & 132 & M & 28 & B & 26.4 & 25.6 \\
\hline 28 & SIZ & 142 & $31^{\circ} \mathrm{N}$ & 137 & M & 23 & B & 27.1 & 26.1 \\
\hline 29 & JAV2 & 116 & $11^{\circ} \mathrm{S}$ & 129 & M & 27 & B & 25.9 & 25.3 \\
\hline 30 & NMA & 148 & $19^{\circ} \mathrm{N}$ & 147 & M & 32 & B & 28.7 & 27.1 \\
\hline 31 & SMA & 146 & $13^{\circ} \mathrm{N}$ & 151 & M & 27 & B & 29.3 & 27.5 \\
\hline 32 & JF1 & 233 & $48^{\circ} \mathrm{N}$ & 6 & M & 5 & $\mathrm{C} 1$ & 7.4 & 3.5 \\
\hline 33 & JF2 & 235 & $41^{\circ} \mathrm{N}$ & 8 & $\mathrm{M}$ & 5 & $\mathrm{~W}$ & 7.7 & 4.5 \\
\hline 34 & $\mathrm{CC} 1$ & 289 & $22^{\circ} \mathrm{S}$ & 53 & $\mathrm{M}, \mathrm{S}$ & 9 & $\mathrm{R}$ & 14.5 & 15.3 \\
\hline 35 & $\mathrm{CC} 2$ & 289 & $19^{\circ} \mathrm{S}$ & 54 & $\mathrm{~L}$ & 20 & $\mathrm{C} 2$ & 14.6 & 15.5 \\
\hline 36 & KUR & 153 & $46^{\circ} \mathrm{N}$ & 114 & M & 25 & $\mathrm{~K} 1$ & 23.7 & 23.6 \\
\hline 37 & Kam2 & 157 & $49^{\circ} \mathrm{N}$ & 110 & M & 25 & $\mathrm{~K} 1$ & 23.1 & 23.1 \\
\hline 38 & Kam3 & 162 & $52^{\circ} \mathrm{N}$ & 104 & M & 25 & $\mathrm{~K} 2$ & 22.2 & 22.4 \\
\hline 39 & Kam4 & 162 & $53^{\circ} \mathrm{N}$ & 100 & M & 30 & $\mathrm{G}$ & 21.6 & 22 \\
\hline
\end{tabular}

Reference abbreviation: B, Brudzinski et al., 2007; C1, Cassidy and Waldhauser, 2003; C2, Comte et al., 1999; G, Gorbatov et al., 1994; K1, Kao and Liu, 1995; K2, Kao and Chen, 1995; L, Lallemand et al., 2005; M, Müller et al., 2008; R, Rietbrock and Waldhauser, 2004; S, Sdrolias and Müller, 2006; W, Wang and Rogers, 1994. SR denotes square root model. 


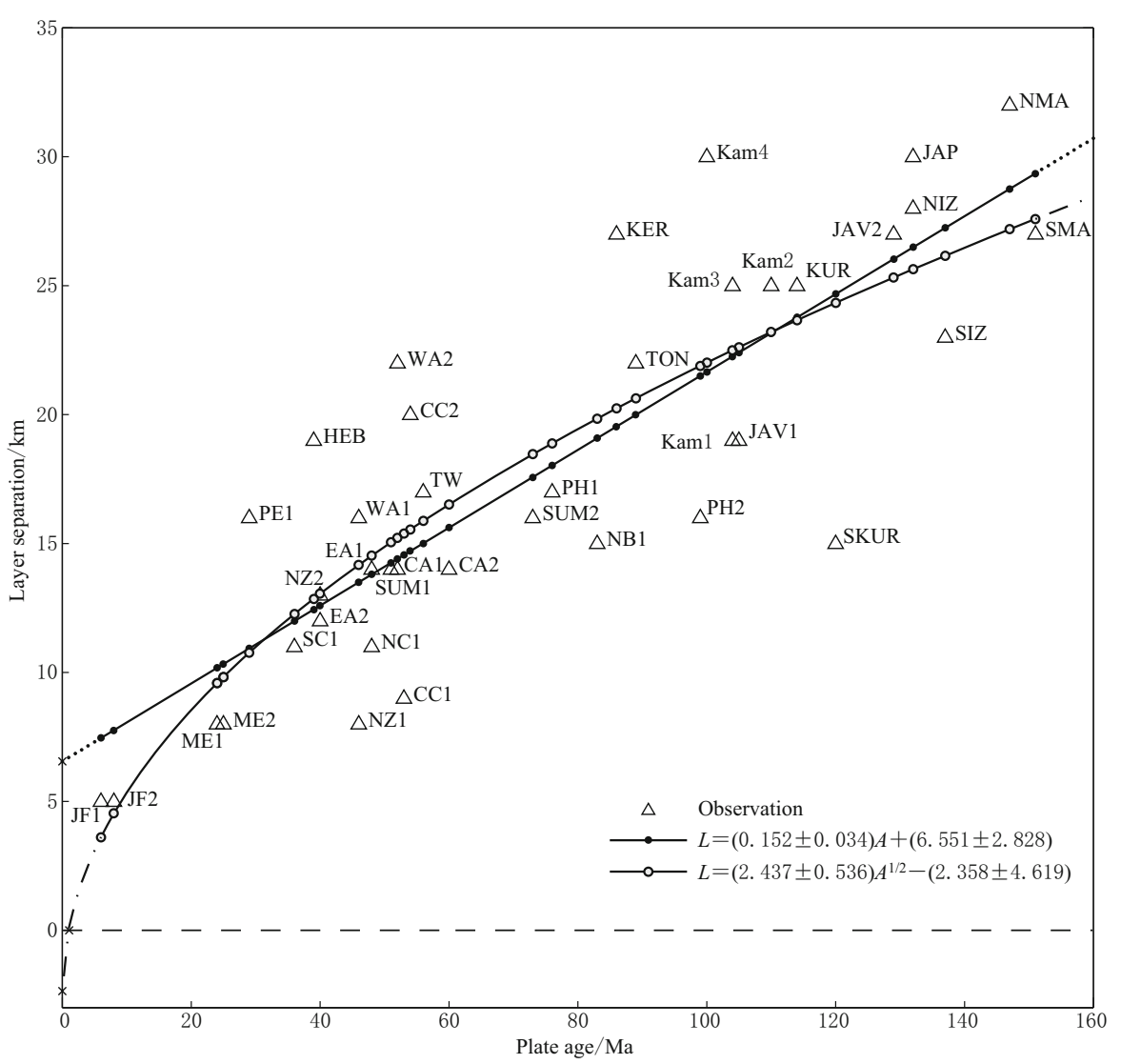

Figure 2 Correlation fittings between layer separation $(L)$ and plate age $(A)$. Solid and open circles denote fitted results of linear and square root models, respectively. Cross symbols on longitudinal axis denote intercepting points for two fittings, and that on abscissa axis denotes the possible plate age that can produce DSZ by the square root model. Dotted and dash-dot lines show the extrapolated trend of linear and square root fitting models, respectively.
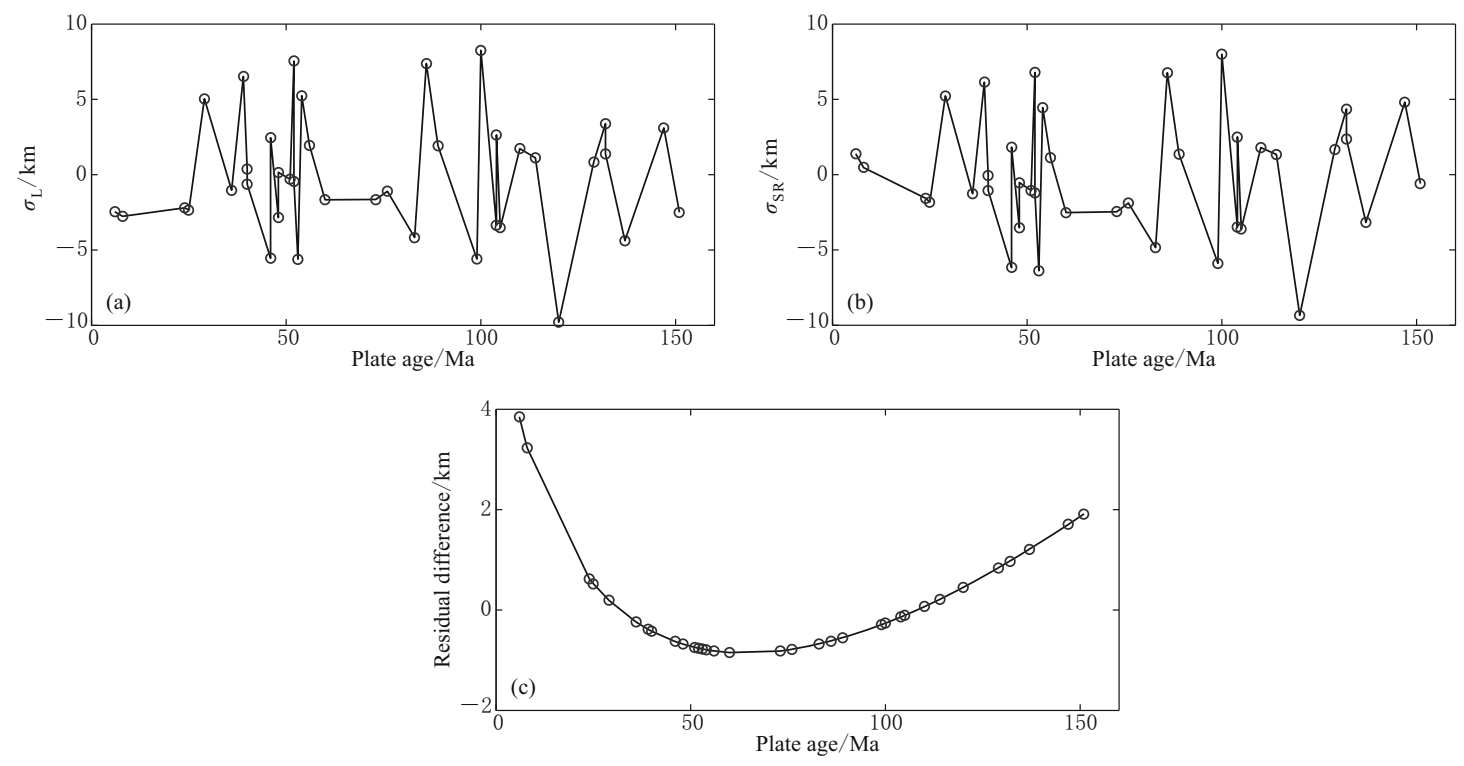

Figure 3 Residuals of two models and their difference. (a) Residual of linear model $\left(\sigma_{\mathrm{L}}\right)$; (b) Residual of square root model $\left(\sigma_{\mathrm{SR}}\right)$; (c) Residual difference of linear and square root models. 
studies have shown that stress state differs significantly from two types of DSZs (Kao and Rau, 1999; Yamasaki and Seno, 2003). Type I DSZs show downdip compression and downdip tension in upper and lower seismic zones, respectively; while type II DSZs show downdip tension in both seismic zones. More recently, we have investigated the correlation among layer separation, stress pattern and subduction parameters, and found that type II DSZs are detected in slabs younger than $60 \mathrm{Ma}$ and the type I DSZs are likely to exist in older slabs (Zhang and Wei, 2011). These results might indicate more complicated role of plate age on subducting lithosphere. Therefore, disregards of the regional or local tectonic stresses, the correlation between DSZs' layer separation and plate age might provide further implications for the physical processes associated with the subducting slab, such as thermal structure and mineral dehydration reactions (Yamasaki and Seno, 2003; Hacker et al., 2003).

Acknowledgements This research is supported by the National Natural Science Foundation of China (grant Nos. 40874047 and 40574047). We thank the anonymous reviewers and the editor, Ms. Lili Tian for their constructive comments.

\section{References}

Abers G A (1996). Plate structure and the origin of double seismic zones. In: Bebout E, Scholl W, Kirby H and Platt P eds. Subduction Top to Bottom, Geophys Monogr Ser. AGU, Washington D.C., 96: 223-228.

Brudzinski M R, Thurber C H, Hacker B R and Engdahl E R (2007). Global prevalence of double Benioff zones. Science 316: 1 472-1 474.

Carlson R L and Johnson H P (1994). On modeling the thermal evolution of the oceanic upper mantle: an assessment of the cooling plate model. J Geophys Res 99: $3201-3214$.

Cassidy J and Waldhauser F F (2003). Evidence for both crustal and mantle earthquakes in the subducting Juan de Fuca plate. Geophys Res Lett 30: 1 095-1 098.

Chen P F, Bina C R and Okal E A (2004). A global survey of stress orientations in subducting slabs as revealed by intermediate depth earthquakes. Geophys J Int 159: 721-733.

Comte D and Suarez G (1994). An inverted double seismic zone in Chile: evidence of phase transition in the subducted slab. Science 263: 212-215.

Comte D, Dorbath L, Pardo M, Monfret T and Haessler H (1999). A double-layered seismic zone in Arica, Northern Chile. Geophys Res Lett 26: 1 965-1 968.

Cruciani C, Carminati E and Doglioni C (2005). Slab dip vs. lithosphere age: No direct function. Earth Planet Sci Lett 238: 298-310.

Gorbatov A, Suarez G, Kostoglodov V and Gordeev E (1994). A double-planed seismic zone in Kamchatka from local and teleseismic data. Geophy Res Lett 21(6): 16751678

Hacker B R, Peacock S M, Abers G A and Holloway S D (2003). Subduction factory 2. Are intermediate-depth earthquakes in subducting slabs linked to metamorphic dehydration reactions? J Geophys Res 108: 2 030-2 045.

Harmon N, Forsyth D W and Weeraratne D S (2009). Thickening of young Pacific lithosphere from high-resolution Rayleigh wave tomography: A test of the conductive cooling model. Earth Planet Sci Lett 278: 96-106.

Hasegawa A, Houriuchi S and Umino N (1994). Seismic structure of the northeastern Japan convergent margin: A synthesis. J Geophys Res 99(B11): 22 295-22 311.

Isacks B and Molnar P (1969). Mantle earthquake mechanisms and the sinking of the lithosphere. Nature 223(5 211): 1 121-1 124.

Jarrard R D (1986). Relations among subduction parameters. Rev Geophys 24(2): 217-284.

Kao H and Chen W P (1995). Transition from interplate slip to double seismic zone along the Kuril-Kamchatka arc. $J$ Geophys Res 100(B7): 9 881-9 903.

Kao H and Liu L (1995). A hypothesis for the seismogenesis of double seismic zone. Geophys J Int 123: 71-84.

Kao H and Rau R J (1999). Detailed structures of the subducted Philippine Sea plate beneath northeast Taiwan: A new type of double seismic zone. J Geophys Res 104(B1): 1 015-1 033.

Kawakatsu H (1986). Downdip tensional earthquakes beneath the Tonga arc: a double seismic zone? J Geophys Res 91(B6): 6 432-6 440.

Lallemand S, Heuret A and Boutelier D (2005). On the relationship between slab slip, back-arc stress, upper plate absolute motion and crustal nature in subduction zones. Geochem Geophys Geosyst 6: Q09006, doi:10.1029/2005GC000917.

Müller R D, Sdrolias M, Gaina C and Roset W R (2008). Age, spreading rates, and spreading asymmetry of the world's ocean crust. Geochem Geophys Geosyst 9: Q04006, doi:10.1029/2007GC001743.

Ohmi S and Hori S (2000). Seismic wave conversion near the upper boundary of the Pacific plate beneath the Kanto district, Japan. Geophys J Int 141: 136-148.

Rietbrock A and Waldhauser F (2004). A narrowly spaced double seismic zone in the subducting Nazca plate. Geophys Res Lett 31: L10608.

Sdrolias M and Müller R D (2006). Controls on back-arc basin formation. Geochem Geophys Geosyst 7: Q04016, doi:10.1029/2005GC001090.

Stein C A and Stein S (1992). A model for the global variation in oceanic depth and heat flow with age. Nature 
359: 123-129.

Suzuki S and Kasahara M (1996). Unbending and horizontal fracture of the subducting Pacific plate, as evidence by the 1993 Kushiro-oki and the 1981 and 1987 intermediate-depth earthquakes in Hokkaido. Phys Earth Planet Inter 93: 91-104.

Turcotte D and Schubert G (2002). Geodynamics. 2nd ed. Cambridge University Press, Cambridge, New York, Melbourne, 456pp.

Wang K (2002). Unbending combined with dehydration embrittlement as a cause for double and triple seismic zones. Geophys Res Lett 29(18): 1 889-1 892.

Wang K and Rogers G C (1994). An explanation for the double seismic layers north of the Mendocino triple junction. Geophys Res Lett 21(2): 121-124.
Wiens D A and Stein S (1983). Age dependence of oceanic intraplate seismicity and implications for lithospheric evolution. J Geophys Res 88(B8): 6 455-6 468.

Yamasaki T and Seno T (2003). Double seismic zone and dehydration embrittlement of subducting slab. J Geophys Res 108(B4): 2 212-2 232.

Zhang K and Wei D (2008). Progresses of the researches and the causing mechanisms on the double seismic zones within the subduction zones around the Pacific ocean. Progress in Geophysics 23(1): 31-39 (in Chinese with English abstract).

Zhang K and Wei D (2011). On the influence factors of double seismic zones. Chinese J Geophys 54(11): 2 8382850 (in Chinese with English abstract). 